\title{
Some clinical trials are driven by fashion, not science
}

\author{
Kirti Kain senior clinical lecturer \\ Division of Cardiovascular \& Diabetes Research, Leeds Institute of Cardiovascular and Metabolic Medicine, University of Leeds, Leeds LS2 \\ 9JT, UK
}

Ioannidis describes the waste in clinical trials. ${ }^{1}$ Some trialssuch as those on vitamin D supplementation-are driven by fashion rather than scientific merit. Despite negative results with various preparations, doses, and frequencies, trials continue to be conducted with different regimens.

Vitamin D supplements are presumed to be a panacea for all known adult chronic medical conditions, even though multiple meta-analyses have indicated otherwise. The US Preventive Services Task Force states that current evidence is insufficient to assess the balance of benefits and harms of screening for vitamin D deficiency in asymptomatic adults. ${ }^{2}$ Furthermore, vitamin D supplements show no overall effect on cardiovascular disease, cancer, or mortality. ${ }^{3}$

Such practice puts patients at unnecessary risk (vitamin D induces calcification of vessel walls in mice), wasting time and money.

Despite this evidence, finances are still directed towards these trials owing to strong research personalities, vested interests, and a deep belief that one day the theory will be proved to be true. However, studies conducted with a fresh different perspective may prove beneficial to patients as well as cost saving. ${ }^{4}$

This principle could be generalised to other trendy but futile clinical trials.

Competing interests: None declared.

1 loannidis JPA. Clinical trials: what a waste. BMJ 2014;349:g7089. (10 December.) LeFevre ML. Screening for vitamin D deficiency in adults: US Preventive Services

Force recommendation statement. Ann Intern Med 2014; published online 25 Nov, doi:10. 7326/M14-2450.

3 Fortmann SP, Burda BU, Senger CA, Lin JS, Beil TL, O'Connor E, et al. Vitamin, mineral, and multivitamin supplements for the primary prevention of cardiovascular disease and cancer: a systematic evidence review for the US Preventive Services Task Force. US Preventive Services Task Force Evidence Syntheses 2013. www.ncbi.nlm.nih.gov/books/ NBK43437/.

4 Kain K. Physical activity, ultraviolet B derived 1,25-vitamin D3 and vascular regeneration. Circulation [forthcoming]

Cite this as: BMJ 2015;350:h288

(c) BMJ Publishing Group Ltd 2015 